\title{
COnVIDa-20: A study on the psychological wound of COVID-19 in university students
}

\author{
1 Padrón, I. ${ }^{1}$, Fraga, I. ${ }^{1}$, Vieitez, L. ${ }^{1}$, Montes, C. $^{2}$, Romero, E. ${ }^{3 *}$ \\ $2 \quad{ }^{1}$ Cognitive Processes \& Behavior Research Group; Department of Social Psychology, Basic \\ 3 Psychology, and Methodology; University of Santiago de Compostela, Santiago de Compostela, \\ 4 Spain \\ $5 \quad{ }^{2}$ Department of Social, Psychology, Basic Psychology, and Methodology; University of Santiago de \\ 6 Compostela, Santiago de Compostela, Spain \\ $7 \quad{ }^{3}$ UNDERISK; Department of Clinical Psychology and Psychobiology, University of Santiago de \\ 8 Compostela, Santiago de Compostela, Spain \\ 9 * Correspondence: \\ 10 Corresponding Author \\ 11 estrella.romero@usc.es
}

12 Keywords: university students, psychological impact, COVID-19, stressors, coping, COnVIDa1320.

14 Abstract

15 An increasing number of studies have addressed the psychological impact of the COVID-19 crisis in 16 the general population. Nevertheless, far less is known about the impact in specific populations such 17 as university students, whose psychological vulnerability has been shown in previous research. This 18 study sought to examine different indicators of mental health in university students during the

19 Spanish lockdown; we also analyzed the main sources of stress perceived by students in relation to

20 the COVID-19 crisis, and the coping strategies adopted when faced with the situation. Data was 21 collected from 932 students (704 women) through a web-based platform. Measures of anxiety (i.e., 22 GAD-7), depression (PHQ-9), irritability and self-perceived change in mental health were administered, as well as ad hoc measures of stressors and coping strategies. Results indicated that students experienced considerable psychological problems during the confinement, with higher rates of emotional difficulties in women and undergraduate students than in men and postgraduates, respectively. Psychological distress was mainly related to several specific domains of stressors, as perceived by the participants: academic future, task overload, worsening of interpersonal conflicts, and restrictions in pleasant social contact; and far less related to the spread of the disease and its consequences for physical health. As regards coping strategies, both reframing skills and daily routines were shown to be the most effective. A path-analysis model integrating stressors, coping, and mental health revealed that coping strategies partially channeled the effect of stressors on psychological health. In general, results suggest that students' psychological health was substantially affected by the COVID-19 situation and that the academic and relational changes were the most notable sources of stress. This study reinforces the need to monitor and promote mental health in university students to boost resilience in times of crisis. Our results on effective coping strategies may inform preventive programs aimed at helping students to deal with challenges like the COVID19 pandemic. 


\section{The psychological wound of COVID-19}

\section{Introduction}

In late December 2019, a new coronavirus disease (COVID-19) emerged in the Chinese city of Wuhan. This new disease, caused by SARS-CoV-2 (Severe Acute Respiratory Syndrome Coronavirus-2), spreads very easily from one person to another and thus rapidly affected other parts of China (Wang et al., 2020a). Within a few weeks, the first cases emerged in other countries, and soon became a global threat. Indeed, in March 2020 the World Health Organization (WHO) declared COVID-19 to be a global pandemic. As of July 6, 2020 (the date of writing this article) about 9,843,073 confirmed cases, including 495,760 deaths, have been reported to the WHO (WHO, 2020a). Following the initial outbreak in China, further outbreaks occurred in Italy and Spain, the first Western countries to be affected, and thus the first countries to face a problem that had hitherto seemed a very distant one to the populations of Western societies. In fact, at the time of writing Spain is one of the three countries (after Belgium and the United Kingdom) with the highest rate of confirmed cases and deaths per million inhabitants (July 6, 2020, cf. WHO, 2020c).

In response to the COVID-19 outbreak, many countries were forced to adopt severe restrictive measures to slow down its propagation. In the case of Spain, the Spanish government declared a state of emergency on March 14th, and a population lockdown became mandatory two days later, creating an unprecedented situation. Citizens only could leave their homes for food, to go to a pharmacy, and for other essential needs. Schools and universities were closed throughout the national territory. Employers (public and private) were obliged to work from home whenever possible, and many lost their jobs temporarily or permanently. In a matter of days, millions of people's lives changed dramatically, leading to important questions about how the pandemic was affecting not only the physical but also the mental health of the population.

Research initially focused mainly on the impact of COVID-19 on physical health and its clinical characterization (e.g., Cao and Li, 2020; Lvov et al., 2020), with studies on the psychological impact of the quarantine subsequently beginning to appear (e.g., Cao et al., 2020; Wang and Zhao, 2020). Findings of all studies (the first of these on the Chinese population, and soon after on other populations of Western countries) revealed a significant and severe increase in depressive symptoms, anxiety, and stress levels due to confinement (e.g., Cao et al., 2020; Chen et al., 2020; Wang and Zhao, 2020) which was generally more pronounced in women than in men (Rodríguez-Rey et al., 2020; Wang and Zhao, 2020; Flesia et al., 2020). Moreover, as recent reviews suggest (Brooks et al., 2020; Hossain et al., 2020), other negative psychological effects, such as post-traumatic stress symptoms, anger, panic, irritability, low self-esteem, and lack of self-control, are commonly found among individuals affected by physical isolation. Data from other pandemics and natural disasters revealed similar effects (see Brooks et al., 2020, for a review). A recent technical report on the Spanish population between 18 to 75 years of age, starting 26 days after the first state of emergency, also revealed significant rates of symptoms of depression $(22.1 \%)$ and anxiety (19.6\%) (Valiente et al., 2020). Importantly, results from this and other studies (e.g., Ozamiz-Etxebarria et al., 2020; Rodríguez-Rey et al., 2020; Flesia et al., 2020) reveal that not all groups were affected in the same way, with young adults (18-24) being more affected compared to other age groups.

To design action plans aimed at protecting and helping citizens who may be affected in different ways by these types of situations, it is first necessary to establish the specific effects of the pandemic in different populations. Interestingly, although studies on the general population are accumulating, the impact on university students is still not well known. There is, however, an abundance of work indicating that most mental health disorders have first onset in young adulthood (e.g., Kessler et al., 2001; Eisenberg et al., 2007). Several studies have also reported that students have consistently 
higher levels of mental health problems than the general population (Overbeek et al., 2003; Zivin et al., 2009; Auerbach et al., 2016). Moreover, research in this field notes the importance of personal and psychosocial factors in the emergence and development of mental disorders in university students (Galindo et al., 2009). Besides academic issues, university students are exposed to multiple stressors which are unique to this developmental period, such as the abandonment of the family home, adjusting to new social and geographical environments, making new friends and social relationships, life-stage transitions, time management, economic resources, etc. (Beiter et al., 2015; Fried, 2020). The lockdown substantially affected these conditions, and the well-being of the university student population would also be expected to have been affected. In brief, university students constitute a population which is particularly vulnerable in terms of mental health, one that even before the pandemic showed a high prevalence of mental disorders. Moreover, many universities suspended normal class-based teaching and moved online, with the result that the lives of students changed drastically (Elmer et al., 2020) and their psychosocial functioning was severely disrupted. It is within this situation, then, that we ask how students' psychological health might have been affected by the pandemic and the confinement.

Thus far only a few papers have addressed this issue specifically. Recent studies on Chinese undergraduate students reported higher levels of anxiety during the COVID-19 outbreak (e.g., Cao et al., 2020; Wang and Zhao, 2020). In Cao et al. study, for example, the authors found that $24.9 \%$ of students experienced symptoms of anxiety, with $0.9 \%$ of cases being severe and $21.3 \%$ mild anxiety. Moreover, it was reported that some factors, such as place of residence, source of parental income, whether living with parents, and having a relative or an acquaintance infected with COVID-19, were associated with increased anxiety. Another recent study, looking at the initial psychological impact of the COVID-19 outbreak on a population of Spanish university students (77\%), academic staff (13\%), and administrative staff (9\%), revealed significantly higher anxiety, depression and stress scores in the students than in the other two groups (Odriozola-González et al., 2020). Meanwhile, Elmer et al. (2020) analyzed changes in social networks and mental health in a sample of Swiss undergraduate students during the COVID-19 crisis (two weeks after the lockdown) in relation to the two preceding years. They also analyzed individual and social factors associated with changes in mental health during the outbreak. In line with previous work, students were found to feel more depressed, anxious, stressed, and lonely than half a year before, and these negative effects were more prominent in women. Also, concerns about family and friends, future careers, living alone, and having less social contact and support, were linked to worse mental health. Even though some studies have not found significant changes in students' mental health during the crisis (Fried, 2020), the general results are congruent with previous research on the psychological impact of previous pandemics (SARS, N1H1) in China (see for example, Jia et al., 2003; Wong et al., 2007; Li et al., 2011).

Although a small number of studies have focused on students populations, we know very little about the specific sources of stress that affected university students during the most acute stage of the crisis, and about the differential impact that these had on the psychological well-being of students. In addition to the stressors present in the general population, such as prolonged isolation periods, fear of infection, frustration and boredom, inadequate information (excess or confusing information), financial loss, and inadequate supplies, as noted by Brooks et al. (2020) and Hossein et al. (2020), university students were also greatly affected by significant academic changes resulting from the pandemic. All Spanish universities suspended face-to-face teaching and moved to online classes and examinations, a transition likely to have had a serious impact on students' feelings of anxiety and uncertainty. As Sahu (2020) has observed, the quality of online education, and its consequences, is a critical issue here, because students without adequate Internet access will experience even more stress, which can have detrimental effects on their academic performance and achievement, as well as 
131 on their mental health. We might add that not all individuals possess equal levels of technological

132 proficiency or confidence, and that the Internet itself was often slow and unreliable during this

133 period, all of which meant that the interactive online environment was sometimes a less than optimal

134 experience.

135 With respect to these specific sources of stress, a study by Okruszek et al. (2020) with Polish young 136 adults found that the COVID-19 risk perception (e.g., contact risk, severe symptoms risk, financial 137 problem risk) and the feeling of loneliness led to affective responses to the situation during the first

138 two weeks of the crisis. However, it is also interesting to note that some individual stressors, such as 139 work overload, strict schedules, Fears of Missing Out on social life (FoMO) or competition among 140 students might in fact have been mitigated during the crisis situation for some students (Elmer et al., 141 2020).

142 There is also little prior evidence about coping strategies used by young adults in this situation. A 143 strategy such as positive coping style was seen to be a protective factor in a general population (Fried et al., 2020) but very little is known about what happens with university students. Furthermore, we do not know the extent to which such strategies might have been effective in cushioning the impact of the COVID-19 crisis. For all the above reasons, the present study was conducted, and had three main goals. The first of these was to study the psychological impact of the COVID-19 pandemic on mental health in a sample of Spanish university students after six weeks of quarantine. The second was to analyze the main sources of stress associated with the COVID-19 context, including stressors arising from the pandemic, measures of social isolation, and changes experienced by students in the academic environment. Finally, we sought to address the issue of which coping strategies were used by students, and how such strategies were related to psychological health during the lockdown. Results were expected to help explore questions of how psychological health was affected during the acute part of the crisis, as well as which stressors and coping behaviors may explain the differences in mental adjustment when faced with the challenges of COVID-19.

\section{$2 \quad$ Method}

\section{$\begin{array}{lll}157 & 2.1 & \text { Participants }\end{array}$}

158

159

160

161

162

163

164

165

166

167

168

169

170

\section{1}

172

173

This study forms part of the wider COnVIDa-20 project, which aims to identify the psychosocial needs and challenges, plus the skills and resources, of Spanish university students during the COVID-19 pandemic (https://www.usc.gal/pcc/web/index_en.html). A total of 932 Spanish students participated in the current survey, the majority being women (see Table 1), and with all levels of university education represented. Most participants were students from one of the 3 public universities of the Autonomous Region of Galicia, an area in the Northwest of Spain. They were classified into 5 groups according to the branch of knowledge to which their undergraduate, master or PhD program belonged: Arts and Humanities, Experimental Sciences, Health Sciences, Engineering and Architecture, and Social and Legal Sciences. A large percentage of the students (56.0\%) moved back to their parents' home during the pandemic and reported having lived with high risk COVID-19 people $(83.4 \%)$ or being part of the high-risk population themselves $(15.1 \%)$. While most of the participants had not suffered the COVID-19, 22.8\% had lived in an environment with an infected person close by.

\subsection{Variables and instruments}

For the purposes of the present study, measures of psychological health, psychosocial stressors, and coping strategies were administered in the context of the broader COnVIDa-20 project. 


\subsubsection{Psychological health}

Four measures were used as indicators of psychological health. Specifically, instruments for the assessment of anxiety, depression, irritability, and self-perceived change in psychological health were administered.

\subsubsection{Anxiety}

Students were asked to respond to the 7-item Generalized Anxiety Disorder Scale (GAD-7; Spitzer et al., 2006). On the GAD-7 scale, symptoms of anxiety over the last 15 days (e.g., "Feeling nervous, anxious, or on edge") were reported using a 4-point Likert rating scale ranging from 0 (not at all) to 3 (almost every day), and thus total scores ranged from 0 to 21 . Scores of 5, 10, and 15 were taken as the cut-off points for mild, moderate, and severe anxiety, respectively. When used as a screening tool, scores of 10 or higher were taken as suggestive of a significant pattern of anxiety (GarcíaCampayo et al., 2010). Cronbach's $\alpha$ in this study was $0.89(\mathrm{MIC}=0.54)$.

\subsubsection{Depression}

The Patient Health Questionnaire (PHQ-9; Kroenke et al., 2001) was administered as a measure of depression. Taking a 15-day period as a reference, participants were asked to rate the presence of depressive symptoms (e.g., "Feeling down, depressed, or hopeless") using a 4-point Likert scale, from 0 (not at all) to 3 (nearly every day), and thus total scores ranged from 0 to 27 (Cronbach's $\alpha=$ 0.87 , MIC $=0.44)$. Scores of 5, 10, 15 and 20 were considered as cut-off points for mild, moderate, moderately severe, and severe symptoms, with scores of 10 or higher being indicative of possible depression.

\subsubsection{Irritability}

Since feelings of irritability have also been described as common effects of the isolation measures in health-related crises (Brooks et al., 2020), the Brief Irritability Test (BIT; Holtzman et al., 2015) was administered. This scale is composed of 5 items (e.g., "I have been feeling like I might snap") with a 6-point Likert scale from 1 (never) to 6 (always). Cronbach's $\alpha$ was 0.92 , MIC $=0.71$.

\subsubsection{Self-perceived change in mental health}

In order to measure subjective changes associated with the COVID-19 situation specifically, we asked students whether they had perceived changes in their mental health during quarantine, using a Likert scale ranging from 1 (my mental health is much worse) to 5 (my mental health is much better).

\subsubsection{Stressors associated with the COVID-19 context}

We developed 26 items to assess possible sources of stress during the quarantine. Participants had to indicate, on a Likert scale, the extent to which they had been disturbed by these during the quarantine, with 1 being "not at all" and 4 "a lot". These items were subjected to Principal Components Analysis with Varimax Rotation. Both scree test and Kaiser's criteria recommended a meaningful 5-factor solution, which grouped the stressors in the following domains: Academic stressors (e.g., "Not receiving the academic training that one expected"), Social distancing (e.g., "Being required to stay at home for so long"), Pandemic (e.g., "The risk that either you or people close to you might become infected by COVID-19"), General overload (e.g., "Lack of free time") and Interpersonal conflicts (e.g., "The intensification of family conflicts"). Scales were created for the five domains by averaging the items aligned with each factor, with Cronbach's $\alpha$ ranging from 0.69 (Interpersonal conflicts) to 0.80 (Academic stressors), and MIC ranging from 0.34 (Social 
215 distancing) to 0.40 (Academic stressors). The distribution of items across scales is shown as

216 supplementary material (Table $1 \mathrm{~S})$.

\section{2.2.3 Coping strategies in the COVID-19 context}

218 A set of 14 items was administered to assess the strategies displayed by participants in dealing with

219 difficulties encountered in the COVID-19 situation. The items were mainly based on the Brief COPE

220 questionnaire (Carver, 1997), and encompassed strategies potentially relevant to students in the

221 quarantine: for instance, emotional support ("Looking for understanding and emotional support from

222 others"), trying to actively improve the situation ("Concentrating my efforts on looking for a solution

223 that might resolve the difficulties I'm facing"), instrumental support ("Trying to get help and advice

224 from other people"), self-distraction ("Doing something to distract me from the difficulties I'm

225 facing"), substance use ("Consuming alcohol or other substances to feel better"), spiritual attitude

226 ("Trying to find solace in my spiritual or religious beliefs"), venting ("Expressing my negative

227 feelings"), humor ("Trying to laugh at the situation"), and acceptance ("Accepting the reality of the

228 fact that this is happening and adapting myself to the situation"). We also developed additional items

229 specifically suited to the quarantine situation: routine maintenance ("Trying to maintain routines and

230 schedules"), self-care ("Taking care of my health (nutrition, exercise...) to be psychologically

231 stronger") and helping others ("Helping others with their own difficulties"). The items were rated on

232 a 4-point Likert scale, from 0 (not used) to 3 (used a lot). Principal Component Analysis with

233 Varimax rotation led to the identification of four domains, based on scree and Kaiser's rules: Other-

234 oriented coping (e.g., "Trying to get help and advice from other people"), Reframing (e.g., "Looking

235 for something good in what is happening"), Disengagement Activities (e.g., "Doing something to

236 distract me from the difficulties I'm facing") and Routines (e.g., "Trying to maintain routines and

237 schedules"). According to this distribution, items were averaged as a means of composing four

238 coping scales, with Cronbach's $\alpha$ ranging from 0.57 (Reframing) to 0.72 (Other-oriented), and MIC

239 ranging from 0.31 (Reframing) to 0.40 (Other-oriented). The final scales are shown as supplementary

240 material (Table 2S).

\section{$241 \quad 2.3 \quad$ Procedure}

242 The questionnaires were conducted using an internal web application, which was available online 243 from April 27th to May 27th. Students were invited to participate mainly via WhatsApp and were 244 encouraged to spread the link to other students using the same platform, although other social media 245 platforms like Twitter were also used. Hence a snowballing technique was used.

246 This study was approved by the Bioethics Committee of the Universidade de Santiago de

247 Compostela, and prior to beginning the questionnaire participants were provided with the aims and

248 requirements of the study. They were also asked to give their explicit agreement to participate in the

249 study and were informed that participation was completely anonymous and voluntary. On average,

250 the survey took 20 minutes to complete and there was no reward or compensation for participating.

\section{$251 \quad 2.4 \quad$ Data analysis}

252 Firstly, descriptives for the stressors, coping domains and indicators of psychological health were computed, with specific focus on percentages of participants scoring high in the measures which provided cut-off points, i.e., anxiety and depression. Second, a multivariate path model was used to examine the relationships among sources of stress, coping strategies, and psychological health. Specifically, the significance of direct and indirect effects was tested through a path analysis in AMOS v24 using maximum likelihood bootstrapping techniques (5,000 bootstrap iterations) and 
bias-corrected 90\% confidence intervals (Preacher and Hayes, 2008). Several fit indices were used to test the model fit, including the $\chi^{2}$ statistic, comparative fit index (CFI), and root mean square error of approximation (RMSEA). Models with a CFI value of 0.90 or higher (Hu and Bentler, 1999) and a RMSEA value below 0.08 (Browne and Cudeck, 1993) were considered to have an acceptable fit.

\section{Results}

\subsection{Descriptives for the studied variables and rates of psychological problems}

Table 2 sets out main descriptives for the measures of psychological health, sources of stress, and coping strategies.

Regarding the analysis of stressors, this shows that academic stressors were rated as the most disturbing, on average, whereas interpersonal conflicts were the least disturbing. As for coping strategies, the involvement in disengagement activities (distracting, relaxing) was the most widely used by students during the quarantine, whereas the setting of healthy routines was reported to have been the least used.

The descriptive statistics for each of the specific stressors and coping strategies are presented as supplementary material (Tables $1 \mathrm{~S}$ and 2S). Among the stressors, the highest mean was achieved by "Uncertainty about the evaluation of the subjects you are taking" (mean $=3.45)$, followed by "The economic future of society as a consequence of the crisis" (mean = 3.40), "Uncertainty about the COVID-19 crisis" (mean = 3.36) and "Lack of face-to-face contact with loved ones" (mean = 3.30). Among the coping strategies, "Accepting the reality of the fact that this is happening and adapting myself to the situation" was the most used (mean =2.02). Other strategies with high means were "Doing something to distract me from the difficulties I'm facing" (mean = 1.88), "Doing relaxing activities" (mean $=1.73)$, and "Helping others with their own difficulties" (mean $=1.72)$.

The means for the scales which indicate emotional difficulties (anxiety, depression, irritability) are high compared to those reported in previous studies on community populations (Löwe et al., 2008; García-Campayo et al., 2010; Holtzman et al., 2015). When the cut-offs for anxiety are taken into account, $61.2 \%$ of participants scored equal to or higher than 10 , i.e., the cut-off usually considered for identifying significant anxiety (i.e., García-Campayo et al., 2010) according to the norms of the scale; specifically, $38.8 \%$ showed moderate anxiety, and $22.4 \%$ severe anxiety. As for the depression scale, $65.8 \%$ of participants scored equal to or higher than 10 , which is the usual cut-off taken as a reference for depression screening (Manea et al., 2012): 23.4\% showed symptoms that were moderate, $25.2 \%$ ones that were moderately severe, and $17.2 \%$ severe symptoms.

When rates for anxiety and depression are compared across genders, significant differences are found. For anxiety, $63.8 \%$ of women and $52.8 \%$ of men scored above the cut-off $\left(\chi^{2}=7.79,1 \mathrm{df}, p<\right.$ $0.006)$. For depression, $68.0 \%$ of women and $58.8 \%$ of men surpassed the cut-off $\left(\chi^{2}=5.68,1 \mathrm{df}, p<\right.$ $0.02)$. The "others" gender could not be introduced into the comparisons due to the small size of the group.

Differences were also found for the level of university studies $\left(\chi^{2}=12.02,2 \mathrm{df}, p<0.002\right)$; the rates for anxiety were $63.5 \%$ (undergraduates), $45.1 \%$ (postgraduates), and $46.7 \%$ (PhD students). For depression, the rates were $68.3 \%, 47.9 \%$, and $50 \%$, respectively $\left(\chi^{2}=15.43,2 \mathrm{df}, p<0.001\right)$. No differences were found across branches of academic knowledge. 
The scores for self-perceived changes indicate that most participants felt that their mental health actually changed during the COVID-19 crisis, with a mean of 2.19 within a range from 1 (change to much worse) to 5 (change to much better). In terms of percentages, $14.7 \%$ perceived that they were much worse, $57.5 \%$ worse, $22.7 \%$ did not perceive any change, $4.2 \%$ perceived that they were better, with only $1 \%$ reporting that they felt much better.

Additional analysis by gender revealed that the mean change in women was worse than for men $(2.15$ vs. $2.32 ; F[1,822]=7.25, p<0.008)$. No differences were found across university levels or branches of academic knowledge.

\subsection{Multivariate path model}

With the aim of analyzing how the different domains of stressors and coping strategies might have impacted psychological health, we then performed a path analysis. Gender and age were used as covariates in the model in order to control for effects on anxiety, depression, irritability, and selfperceived change. First, we tested a saturated model in which all the paths (both direct and indirect) were included. We then tested the fit of a reduced model, in which only the significant paths and covariances were retained.

Table 3 presents the correlations between the constructs used in the path analysis. All sources of stress, as well as coping strategies, correlated significantly with anxiety, depression, irritability, and self-perceived change, except for disengagement activities, which were only associated with depression $(r=-0.09)$ and self-perceived change $(r=0.09)$. The highest correlation was found between interpersonal conflict and irritability $(r=0.48)$, and the lowest between disengagement activities and depression $(r=-0.09)$. As expected, anxiety, depression, and irritability correlated strongly with each other $\left(r_{\mathrm{s}}\right.$ ranged from 0.63 to 0.75$)$ and were negatively correlated to selfperceived change ( $r_{\mathrm{s}}$ ranged from -0.57 to -0.50$)$.

Figure 1 shows the final model in which only the significant paths and covariances were retained. The final model fits the data well, $\chi^{2}=237.40, \mathrm{df}=37, p<0.001$, RMSEA $=0.08, \mathrm{CFI}=0.95$, and predicted variation in health to an acceptable degree, accounting for $31-38 \%$ of the explained variance in irritability and anxiety, respectively.

Standardized regression $(\beta)$ weights were used to examine the size and significance of the direct effects of the stressors specified within the model (Byrne, 2016). Tables 4 and 5 present coefficients from the path analysis model, after controlling for gender and age.

Results of the path analysis revealed that pandemic stressors showed a significant positive association with all the coping strategies. Social distancing was positively associated with otheroriented strategies, routines, and disengagement activities, but negatively associated with reframing. In contrast, general overload had a significant negative association with routines and disengagement activities, and a positive one with other-oriented strategies. Academic stressors only had a direct and significant negative effect on routines.

Regarding the coping-psychological health pathway, reframing was associated with better psychological health consistently across measures, that is, less anxiety, less depression, less irritability, and fewer unfavorable changes in mental health. The negative association of routines with depression was particularly strong $(\beta=-0.19, p<0.001)$. Conversely, other-oriented coping predicted higher levels of psychological ill-being for anxiety and self-perceived health change. The coping 
domain involved in psychological outcomes to the least extent was that of disengagement activities,

340 which had no significant effect.

341 Furthermore, once adjusted for confounding variables, decomposition of total effects (Table 6)

342 showed that both the direct and indirect effects of sources of stress on psychological measures were

343 statistically significant $(p<0.05)$, providing a definite pattern: Higher general overload, social

344 distancing, interpersonal conflict, and academic stressors were significantly associated with higher

345 anxiety, depression, and irritability, and worse self-perceived change. Pandemic stressors, in turn,

346 only had a direct effect on anxiety, $\beta=0.092, p<0.001$.

347 The final model revealed thirteen indirect pathways among sources of stress and psychological health measures throughout the model; however, the proportion of mediated effects $(\%)$ were weaker in magnitude, ranging from $7.34 \%$ to $18.84 \%$. The indirect effects of social distancing $(\beta=-0.002,90 \%$ CI: $-0.021,0.016, p>0.10)$ and the pandemic $(\beta=-0.005,90 \% \mathrm{CI}:-0.019,0.009, p>0.10)$ on depression and anxiety, respectively, were no longer significant.

A growing number of studies have addressed the psychological effects of the COVID-19 crisis, but very little is known about the impact on university students, despite the fact that students might be expected to be greatly affected by the pandemic conditions and by the policies implemented to curtail the spread of the disease. Emergent adulthood is itself a developmental time and is well-known to be vulnerable to psychological difficulties (Schulenberg et al., 2004); in particular, high rates of mental problems have previously been reported in student populations (Auerbach et al., 2018). The COVID19 crisis led to the closure of universities and forced students not only to change their general life conditions, but also to substantially adjust their daily academic work, long-term projects, and their expectations. Hence, the current study examined the psychological health of university students during the Spanish quarantine, considering the specific sources of stress perceived by these students during the crisis, as well as the strategies reported to have been used to cope with the situation of COVID-19.

\subsection{Mental health during the COVID-19 crisis}

Several indicators of mental health were analyzed in this study. On the one hand, we included measures of common psychological problems (anxiety, depression), using standardized measures widely employed in previous research for prevalence purposes (Quon et al., 2015), and also in recent research looking at the COVID-19 crisis (Zhu et al., 2020). On the other hand, we also included a measure of irritability (proneness to anger, annoyance, frustration and aggressive reactions), which previous studies have identified as a possible outcome of social distancing measures (Brooks et al., 2020), especially in young people (Balluerka et al., 2020). Additionally, as a specific indicator of how well-being evolved in relation to the COVID-19 crisis, we asked students about self-perceived changes in their mental health. Across this array of measures, our results consistently suggest that students experienced considerable psychological difficulties during the acute part of the crisis. The numbers for anxiety and depression are very high, with $61.2 \%$ of participants scoring above the GAD-7 usual cut-off, and 65.8\% surpassing the PHQ-9 cut-off. High levels of irritability were also found, and more than $70 \%$ of students reported that their mental health had worsened during the confinement.

380 The fact that students show high rates of psychological problems is consistent with studies conducted 381 on the general population, which have found that young people are psychologically more affected by 
the COVID-19 crisis than older people (Valiente et al., 2020). Those few previous studies that have specifically examined psychological health in university students during the pandemic also tend to report high levels of anxiety, depression, stress (Cao et al., 2020; Odriozola-González et al., 2020) and even suicidality (Patsali et al., 2020). Although, due to the diversity of measures employed, the levels of psychological disturbance previously reported in students' samples are difficult of compare, the rates found in our study seem to be strikingly high. This may be due to the critical time when our data was collected, that is, after more than six weeks of home confinement, and also, perhaps more importantly for the student population, close to the end of the academic year, with final exams to be taken in uncertain and unprecedented conditions.

391 In accordance with past research on general psychological health (Salk et al., 2017), and with some

392

393

394

395

396

397

398

399

400

401

402

403

404

405

406

407

408

409

410

411

412

413

other studies conducted during the COVID-19 crisis (Wang et al., 2020b), higher rates of emotional difficulties were found for women than for men. In the absence of longitudinal data, we cannot disentangle the issue of how far these differences reflect the higher prevalence of common psychological problems in women, and/or gender differences within the impact of the crisis. Notable was the fact that we found differences not only for the basic measures of problems, but also for the measure of self-perceived change, thus suggesting that, in addition to the baseline emotional differences, there may be differences in terms of the response to COVID-19 difficulties. Along these lines, it has been suggested that a higher perception of threat and a greater sensitivity to the loss of control may influence the higher vulnerability of women in situations of crisis and trauma (Olff et al., 2007). And, in relation to COVID-19, it has also been suggested that the pandemic may differentially affect women by the worsening of gendered burdens, such as the overload derived from household or caregiving tasks (McLaren et al., 2020).

Our results also indicate that more psychological difficulties are found in undergraduate than in postgraduate students. Apart from age-related differences, which may involve less resilience in the adaptation to drastic changes (Masten et al., 2006), undergraduate students might have been more greatly affected by modifications in teaching and evaluation, as undergraduate learning is usually less autonomous and more guided by lectures and other on-site activities which were banned during the confinement. Moreover, studies conducted in pre-pandemic times have reported more psychological problems in undergraduates than in graduate students (Wyatt and Oswalt, 2013), so differences in pre-existing mental health cannot be precluded. In any case, this pattern of results suggests the need to promote mental health in the undergraduate population, in that they stand out as the student group most susceptible to emotional difficulties, in both ordinary and crisis periods.

\subsection{Stress and coping during the COVID-19 crisis}

Although this study could not ensure the representativity of the sample, overall, our results suggest that psychological distress was high among university students during the Spanish quarantine. With the aim of making advances in the identification of determinants which may help to explain these disturbances, we explored the sources of stress as perceived by students during the pandemic situation. Our results showed that psychological difficulties were related to the experience of several domains of stressors, such as academic future, task overload, worsening of interpersonal conflicts, and restrictions in pleasant social contact. So, it seems that the personally relevant stressors, linked to difficult and troubling academic and social experiences, were the ones that were most involved in students' psychological problems. These results are in line with pre-pandemic reports on the main concerns and stressors for university students (Beiter et al., 2015); the findings of the other studies conducted during the pandemic have also pointed to academic and relational worries as the main determinants of alterations in the mental health of students (Elmer et al., 2020). 


\section{The psychological wound of COVID-19}

According to our results, stressors related to the spread of the disease (lethality, risk of contagion) were less associated with psychological distress; students seemed to be less vulnerable to health and society-wide concerns which, although relevant, seemed to them to be more distant and to have fewer personal implications. The message that young people were less affected by the disease (Liao et al., 2020) was quickly disseminated from the very first weeks of the pandemic; also, low risk appraisals and a sense of invulnerability have previously been described as features of adolescents and young adults (cf. Millstein and Halpern-Felsher, 2002; Lapsley and Hill, 2010). Age-related processes and widespread media messages, then, might both have affected the psychological resistance of students in relation to the threats of the disease. These same processes might help explain the high number of contagions in young Spanish people once the social restrictions were reduced (Minder, 2020).

This study also examined coping strategies, i.e., the efforts made by students to deal with the stressful conditions arising from the COVID-19 crisis. We used a measure specifically aimed at capturing context-relevant coping, which allowed us to inductively identify four ways of coping during the acute phase of the crisis: focusing on others to ask for support or to offer help (Other-oriented), accepting the uncontrollable nature of the crisis, focusing on positive dimensions, and trying to take steps to change what is controllable (Reframing), involving in activities which can help one to detach oneself from stressful situations (Disengagement activities), and setting up a healthy structure in one's daily life (Routines). It is remarkable that the first three dimensions, based closely on the Brief COPE (Carver, 1997), and less specifically related to COVID-19 context, tightly resemble other coping solutions found in emerging adulthood (e.g., Jenzer et al., 2019), which may indicate that they can be seen as robust coping domains for this life stage.

When we analyze the relationships between coping and psychological health, we find that, despite being one of the most used types of coping, disengagement activities are almost unrelated to psychological adjustment. In the literature on coping, some controversies remain as to the efficacy of disengagement coping to deal with different kinds of life stressors (Waugh et al., 2020); in the specific context of the pandemic, our results suggest that devoting time to distracting/relaxing activities might have some minimal effect on the psychological health.

We also found that another of the most used coping strategies, other-oriented coping, is associated with higher levels of psychological disturbances. This is a rather unexpected result, since social support is usually considered a protecting mechanism in stressful situations (Ozbay et al., 2007), including the COVID-19 pandemic (Cao et al., 2020), and in demanding academic conditions (Rayle and Chung, 2007). Likewise, helping behaviors have been assumed to be a means of coping with collective crises (Balluerka et al., 2020), as they can be a source of fostering good moods, a sense of self-efficacy, and a way of promoting social integration (Vollhardt, 2009). Nevertheless, our finding that other-oriented coping does not enhance well-being is not an isolated result within research into coping, particularly with young samples (Braun-Lewensohn et al., 2010). It has been tentatively suggested that reliance on others could sometimes be an ultimate resource for severely troubled people who have previously tried other ways of dealing with difficult situations (Okafor et al., 2016). Additionally, it has been proposed that the emphasis on reaching out to others might be an index of personal dependence (Lewis and Frydenberg, 2002) and might hamper the development of more selfreliant coping resources. Although more research on these lines is needed, it is even possible that in a large-scale crisis like COVID-19, where social connectedness is hindered, seeking social support needs to be clearly distinguished from obtaining satisfactory social support; with all the population affected at the same time by the same risks, and with social distancing in force, trying to help or be helped by others may not have been as effective as it might have been in more limited situations of stress. 
Other coping strategies were found to be associated with low levels of mental health problems. One of these is to accept and cognitively re-appraise the situation (reframing), attempting to seize on positive aspects and to solve the problems which remain controllable. This active coping style has been found to be beneficial in a broad body of previous research; it has shown its capacity to predict mental health and achievement outcomes in a number of psychopathological areas (Gaudreau, 2017), it is usually self-perceived as effective by the persons who display it (Crocker et al., 2015), and interventions aimed to boost active coping have proved to be successful for stress management (Jamieson et al., 2018). Based on our results, the promotion of reframing skills could be recommended as a potentially useful way to develop resilient attitudes among university students.

During the acute phases of the pandemic, health agencies and the mass media have recommended setting up regular schedules and routines in daily life (e.g., WHO, 2020b) in terms of work, eating, leisure time, exercising and sleeping, in that these might bring some regularity in the midst of uncertainty, and might prevent perturbations in mood and psychobiological rhythms. Our results seem to endorse such recommendations: students who kept regular schedules and established healthy routines as a way of coping showed better outcomes in mental health. Our results also reinforce the specific connection between routines and mood/depression problems which was highlighted in previous research (Boland et al., 2019). Given that depression is one of the most prevalent disorders in university students, both before and during the pandemic (Auerbach et al., 2018; OdriozolaGonzález et al., 2020), this result might guide preventive interventions to help students remain healthy and to cope with crises such as the COVID-19 confinement.

In general, this study shows that what students do to cope with the situation is relevant to an understanding of individual differences in mental health during the time of COVID-19. In fact, as evidenced by our structural model, the effect of stressors on mental health is conveyed, in part, through students' coping efforts. In other words, coping strategies emerge as proactive actions which may substantially affect the experience of the crisis, thus opening roads for psychological inoculation amidst the COVID-19 pandemic.

\subsection{Limitations and future research}

This study is not exempt from limitations. First, although the sample was of a considerable size and variety in terms of academic fields, educational levels and socioeconomic origins, it was based on a snowballing technique, which cannot guarantee representativeness in terms of the Spanish population of university students analyzed, and this leads us to take the prevalence rates of psychological problems with particular caution. Second, as with most studies in this area, self-reports were the only measurement technique, raising the possibility that shared method variance inflated the associations among variables to some extent. Thirdly, as noted above, this is a cross-sectional study which cannot identify and eliminate the proportion of psychological problems which were already present before the pandemic. The lack of longitudinal data also makes it impossible to accurately identify the directionality of the effects; even when the flow from stressors/coping to mental health is theoretically driven (Carver and Connor-Smith, 2010), and is coherent with a vast number of empirical reports (Cooper, 2017), reciprocal effects cannot be discarded. Perception of stress may be influenced by psychological disturbances, and even more than this, stressful events might be precipitated by psychological problems, according to stress-generation models (Rudolph et al., 2000). For instance, depressed or irritable individuals may worsen interpersonal conflicts during the pandemic due to their inappropriate, unstable or offensive behavior. 
516 Thus, further research should address the bidirectional dynamics between stressors, coping, and 517 mental health. Longitudinal designs will also allow for the delineation of the stability and change of

518 the psychological disturbances as the COVID-19 conditions evolve, in order to ascertain to what 519 extent those psychological difficulties depicted during the first phases of the pandemic were acute 520 peaks or sustained reactions.

521 For now, this study is one the first to concurrently examine stressors, coping strategies, and mental 522 health in university students during a critical point of the crisis. We considered stressors which may 523 be shared by the general population along with student-specific ones; we also measured a plethora of 524 relevant coping behaviors, including active, passive, emotion-centered and problem-centered 525 strategies, and we analyzed a variety of mental health measures. Our results provide a nuanced picture of how students were psychologically damaged during the first weeks of the crisis, when difficulties were the most impactful, and how they tried to face the challenges brought about by COVID-19.

\section{$529 \quad 4.4 \quad$ Implications}

530 Our results have practical implications for interventions in university settings. By delineating the sources of stress and coping behaviors, we may be in a better position to boost endurance during the next phases of the pandemic as well as in any future crisis. Mental problems in university students are not only a matter of community health; psychological disturbances have an influence on academic performance, student retention, graduation rates and career development (Wyatt and Oswalt, 2013), and the university context is a privileged place to promote mental health in emerging adulthood. Our results suggest that monitoring mental health in universities may lead to the identification of many students who are susceptible to benefit from assistance in social/health crises. Counseling services, delivered in online formats (Zhai and Du, 2020), may be a cost-efficient way of reaching vulnerable students; online interventions show the added advantages of addressing other barriers to treatment such as stigma and inconvenience, as pointed out elsewhere (Auerbach et al., 2018). While universities are unlikely to have enough resources for the treatment of severe cases, they might be able to offer screening services, along with first-aid interventions, which may refer students to specialized services when needed.

544 In terms of specific interventions, our results suggest the appropriateness of training in coping skills 545 for acceptance, active coping, and healthy structuring of one's daily life, even when the future is uncertain, and when external schedules are lacking. Different psychological orientations may provide fruitful insights for such interventions, including acceptance and commitment therapy, cognitivebehavioral therapy, and behavioral activation approaches (Polizzi et al., 2020). While students are an asset for universities and more broadly for society, their mental health has been shown to have a certain fragility; the need for prevention and health promotion emerges as a general take-home message from the current evidence on COVID-19 outcomes. 


\section{References}

Auerbach, R.P., Alonso, J., Axinn, W.G., Cuijpers, P., Ebert, D.D., Green, J.G., et al. (2016). Mental disorders among college students in the World Health Organization World Mental Health Surveys. Psychological Medicine 46(14), 2955-2970. doi: 10.1017/S0033291716001665.

Auerbach, R.P., Mortier, P., Bruffaerts, R., Alonso, J., Benjet, C., Cuijpers, P., et al. (2018). WHO World Mental Health Surveys International College Student Project: Prevalence and distribution of mental disorders. J Abnorm Psychol 127(7), 623-638. doi: 10.1037/abn0000362.

Balluerka, N., Gómez, J., Hidalgo, M.D., Gorostiaga, A., Espada, J.P., Padilla, J.L., et al. (2020). "Las consecuencias psicológicas de la COVID-19 y el confinamiento". Servicio de Publicaciones de la UPV.

Beiter, R., Nash, R., McCrady, M., Rhoades, D., Linscomb, M., Clarahan, M., et al. (2015). The prevalence and correlates of depression, anxiety, and stress in a sample of college students. $J$ Affect Disord 173, 90-96. doi: 10.1016/j.jad.2014.10.054.

Boland, E.M., Goldschmied, J.R., Kelly, M.R., Perkins, S., Gehrman, P.R., and Haynes, P.L. (2019). Social rhythm regularity moderates the relationship between sleep disruption and depressive symptoms in veterans with post-traumatic stress disorder and major depressive disorder. Chronobiol Int 36(10), 1429-1438. doi: 10.1080/07420528.2019.1644344.

Braun-Lewensohn, O., Sagy, S., and Roth, G. (2010). Coping strategies among adolescents: Israeli Jews and Arabs facing missile attacks. Anxiety Stress Coping 23(1), 35-51. doi: $10.1080 / 10615800802647601$.

Brooks, S.K., Webster, R.K., Smith, L.E., Woodland, L., Wessely, S., Greenberg, N., et al. (2020). The psychological impact of quarantine and how to reduce it: rapid review of the evidence. Lancet 395(10227), 912-920. doi: 10.1016/S0140-6736(20)30460-8.

Browne, M.W., and Cudeck, R. (1993). "Alternative ways of assessing model fit," in Testing structural equation models, eds. K. Bollen \& K. Long. (Beverly Hills, CA: CA: Sage), 163-162.

Byrne, B.M. (2016). Structural Equation Modelling with Amos: Basic Concepts, Applications, and Programming. New York: NY: Routledge.

Cao, W., Fang, Z., Hou, G., Han, M., Xu, X., Dong, J., et al. (2020). The psychological impact of the COVID-19 epidemic on college students in China. Psychiatry Res 287, 112934. doi: 10.1016/j.psychres.2020.112934.

Cao, W., and Li, T. (2020). COVID-19: towards understanding of pathogenesis. Cell Research 30(5), 367-369. doi: 10.1038/s41422-020-0327-4.

Carver, C.S. (1997). You want to measure coping but your protocol's too long: consider the brief COPE. Int J Behav Med 4(1), 92-100. doi: 10.1207/s15327558ijbm0401_6.

Carver, C.S., and Connor-Smith, J. (2010). Personality and coping. Annu Rev Psychol 61, 679-704. doi: 10.1146/annurev.psych.093008.100352. 
592 Cooper, C., and Quick, J. C. (2017). The handbook of stress and health: A guide to research and 593 practice: John Wiley \& Sons.

594 Crocker, P.R.E., Tammien, K.A., and Gaudreau, P. (2015). "Coping in sport.," in Contemporary advances in sport psychology: A review., ed. S.D.M.S. Hanton. Springer, 28-67. People's Mental Health? - Evidence From Chinese College Students. Frontiers in Psychology 11(1529). doi: 10.3389/fpsyg.2020.01529.

599 Eisenberg, D., Gollust, S.E., Golberstein, E., and Hefner, J.L. (2007). Prevalence and correlates of 600 depression, anxiety, and suicidality among university students. Am J Orthopsychiatry 77(4), 534-542. 601 doi: 10.1037/0002-9432.77.4.534.

602 Elmer, T., Mepham, K., and Stadtfeld, C. (2020, May 6). Students under lockdown: Comparisons of 603 students' social networks and mental health before and during the COVID-19 crisis in Switzerland. 604 doi: https://doi.org/10.31234/osf.io/ua6tq.

605 Flesia, L., Fietta, V., Colicino, E., Segatto, B., and Monaro, M. (2020, April 24). Stable 606 psychological traits predict perceived stress related to the COVID-19 outbreak. doi: 607 https://doi.org/10.31234/osf.io/yb2h8.

610 Galindo, S.B., Moreno, I.M., and Muñoz, J.G. (2009). Prevalencia de ansiedad y depresión en una 611 población de estudiantes universitarios: Factores académicos y sociofamiliares asociados.

612 [Prevalence of anxiety and depressive disorders in university students: Associated academic and 613 socio-family factors]. Clínica y Salud 20(2), 177-187.

614 García-Campayo, J., Zamorano, E., Ruiz, M.A., Pardo, A., Pérez-Páramo, M., López-Gómez, V., et 615 al. (2010). Cultural adaptation into Spanish of the generalized anxiety disorder-7 (GAD-7) scale as a 616 screening tool. Health and quality of life outcomes 8, 8-8. doi: 10.1186/1477-7525-8-8.

617 Gaudreau, P. (2017). Active coping strategies. Encyclopedia of personality and individual 618 differences. Springer.

619 El Camino Health (2020). Establishing a new daily routine during the COVID-19 pandemic. 620 [Online]. http://www.elcaminohealth.org/stay-healthy/blog/establishing-new-daily-routine-during621 covid-19. [Accessed July 10, 2020].

622 Holtzman, S., O'Connor, B.P., Barata, P.C., and Stewart, D.E. (2015). The Brief Irritability Test 623 (BITe): a measure of irritability for use among men and women. Assessment 22(1), 101-115. doi: $624 \quad 10.1177 / 1073191114533814$.

625 Hossain, M., Tasnim, S., Sultana, A., Faizah, F., Mazumder, H., Zou, L., et al. (2020). Epidemiology 626 of mental health problems in COVID-19: a review [version 1; peer review: awaiting peer review]. 627 F1000Research 9(636). doi: 10.12688/f1000research.24457.1. 
628 Hu, L.t., and Bentler, P.M. (1999). Cutoff criteria for fit indexes in covariance structure analysis:

629 Conventional criteria versus new alternatives. Structural Equation Modeling: A Multidisciplinary

630 Journal 6(1), 1-55. doi: 10.1080/10705519909540118.

631 Jamieson, J.P., Crum, A.J., Goyer, J.P., Marotta, M.E., and Akinola, M. (2018). Optimizing stress 632 responses with reappraisal and mindset interventions: an integrated model. Anxiety Stress Coping 633 31(3), 245-261. doi: 10.1080/10615806.2018.1442615.

634 Jenzer, T., Read, J.P., Naragon-Gainey, K., and Prince, M.A. (2019). Coping trajectories in emerging 635 adulthood: The influence of temperament and gender. J Pers 87(3), 607-619. doi: 10.1111/jopy.12419.

Jia, N., Fan, N., and Lu, Z. (2003). A survey of the undergraduate anxiety in the SARS infected areas. J. Hebei Normal Univer. 5, 57-60.

639 Kessler, R.C., Avenevoli, S., and Ries Merikangas, K. (2001). Mood disorders in children and 640 adolescents: an epidemiologic perspective. Biol Psychiatry 49(12), 1002-1014. doi: 10.1016/s0006$641 \quad 3223(01) 01129-5$.

642 Kroenke, K., Spitzer, R.L., and Williams, J.B. (2001). The PHQ-9: validity of a brief depression 643 severity measure. J Gen Intern Med 16(9), 606-613. doi: 10.1046/j.1525-1497.2001.016009606.x.

644 Lapsley, D.K., and Hill, P.L. (2010). Subjective invulnerability, optimism bias and adjustment in 645 emerging adulthood. J Youth Adolesc 39(8), 847-857. doi: 10.1007/s10964-009-9409-9.

646 Lewis, R., and Frydenberg, E. (2002). Concomitants of failure to cope: what we should teach adolescents about coping. Br J Educ Psychol 72(Pt 3), 419-431. doi: 10.1348/000709902320634483.

Li, J., Chen, S., Zhu, L., and Zhang, W. (2011). Investigation of knowledge of prevention and control and psychological anxiety about H1N1 influenza among college students in a university, Zhengzhou. Modern Prevent. Med. 38, 3036-3042.

651 Liao, J., Fan, S., Chen, J., Wu, J., Xu, S., Guo, Y., et al. (2020). Epidemiological and Clinical 652 Characteristics of COVID-19 in Adolescents and Young Adults. The Innovation 1(1), 100001. doi: 653 https://doi.org/10.1016/j.xinn.2020.04.001.

654 Löwe, B., Decker, O., Müller, S., Brähler, E., Schellberg, D., Herzog, W., et al. (2008). Validation 655 and standardization of the Generalized Anxiety Disorder Screener (GAD-7) in the general 656 population. Med Care 46(3), 266-274. doi: 10.1097/MLR.0b013e318160d093.

657 Lvov, D.K., Alkhovsky, S.V., Kolobukhina, L.V., and Burtseva, E.I. (2020). [Etiology of epidemic 658 outbreaks COVID-19 on Wuhan, Hubei province, Chinese People Republic associated with 2019$659 \mathrm{nCoV}$ (Nidovirales, Coronaviridae, Coronavirinae, Betacoronavirus, Subgenus Sarbecovirus): 660 lessons of SARS-CoV outbreak.]. Vopr Virusol 65(1), 6-15. doi: 10.36233/0507-4088-2020-65-1-666115.

662 Manea, L., Gilbody, S., and McMillan, D. (2012). Optimal cut-off score for diagnosing depression 663 664 with the Patient Health Questionnaire (PHQ-9): a meta-analysis. Cmaj 184(3), E191-196. doi: 10.1503/cmaj.110829. 


\section{The psychological wound of COVID-19}

665 Masten, A.S., Obradović, J., and Burt, K.B. (2006). "Resilience in Emerging Adulthood:

666 Developmental Perspectives on Continuity and Transformation," in Emerging adults in America:

667 Coming of age in the 21 st century. (Washington, DC, US: American Psychological Association),

$668 \quad 173-190$.

669 McLaren, H.J., Wong, K.R., Nguyen, K.N., and Mahamadachchi, K.N.D. (2020). Covid-19 and 670 women's triple burden: Vignettes from Sri Lanka, Malaysia, Vietnam and Australia. Social Sciences 671 9(5), 87. doi: https://doi.org/10.3390/socsci9050087.

672 Millstein, S.G., and Halpern-Felsher, B.L. (2002). Perceptions of risk and vulnerability. J Adolesc 673 Health 31(1 Suppl), 10-27. doi: 10.1016/s1054-139x(02)00412-3.

674 Minder, R. (2020). Spain's Reopening Stumbles as Virus Cases Rise Among Young People. The New 675 York Times. Retrieved from https://www.nytimes.com/2020/07/23/world/europe/spain-coronavirus676 reopening.html

677 Odriozola-González, P., Planchuelo-Gómez, Á., Irurtia, M.J., and de Luis-García, R. (2020).

678 Psychological effects of the COVID-19 outbreak and lockdown among students and workers of a

679 Spanish university. Psychiatry Research 290, 113108. doi:

680 https://doi.org/10.1016/j.psychres.2020.113108.

681 Okafor, E., Lucier-Greer, M., and Mancini, J.A. (2016). Social stressors, coping behaviors, and depressive symptoms: A latent profile analysis of adolescents in military families. J Adolesc 51, 133143. doi: 10.1016/j.adolescence.2016.05.010.

Okruszek, Ł., Aniszewska-Stańczuk, A., Piejka, A., Wiśniewska, M., and Żurek, K. (2020, April 10).

Olff, M., Langeland, W., Draijer, N., and Gersons, B.P. (2007). Gender differences in posttraumatic stress disorder. Psychol Bull 133(2), 183-204. doi: 10.1037/0033-2909.133.2.183.

696 Ozbay, F., Johnson, D.C., Dimoulas, E., Morgan, C.A., Charney, D., and Southwick, S. (2007).

697 Social support and resilience to stress: from neurobiology to clinical practice. Psychiatry (Edgmont) 698 4(5), 35-40.

699 Patsali, M.E., Mousa, D.-P.V., Papadopoulou, E.V.K., Papadopoulou, K.K.K., Kaparounaki, C.K., 700 Diakogiannis, I., et al. (2020). University students' changes in mental health status and determinants 701 of behavior during the COVID-19 lockdown in Greece. Psychiatry Research, 113298. doi:

702 https://doi.org/10.1016/j.psychres.2020.113298. 
Polizzi, C., Lynn, S.J., and Perry, A. (2020). Stress and coping in the time of COVID-19: Pathways to resilience and recovery. Clinical Neuropsychiatry: Journal of Treatment Evaluation 17(2), 59-62.

Preacher, K.J., and Hayes, A.F. (2008). Asymptotic and resampling strategies for assessing and comparing indirect effects in multiple mediator models. Behav Res Methods 40(3), 879-891. doi: 10.3758/brm.40.3.879.

Quon, B.S., Bentham, W.D., Unutzer, J., Chan, Y.F., Goss, C.H., and Aitken, M.L. (2015). Prevalence of symptoms of depression and anxiety in adults with cystic fibrosis based on the PHQ-9 and GAD-7 screening questionnaires. Psychosomatics 56(4), 345-353. doi: 10.1016/j.psym.2014.05.017.

Rayle, A.D., and Chung, K.Y. (2007). Revisiting first-year college students' mattering: Social support, academic stress, and the mattering experience. Journal of College Student Retention: Research, Theory and Practice 9(1), 21-37. doi: 10.2190/X126-5606-4G36-8132.

Rodríguez-Rey, R., Garrido-Hernansaiz, H., and Collado, S. (2020). Psychological Impact and Associated Factors During the Initial Stage of the Coronavirus (COVID-19) Pandemic Among the General Population in Spain. Frontiers in Psychology 11(1540). doi: 10.3389/fpsyg.2020.01540.

Rudolph, K.D., Hammen, C., Burge, D., Lindberg, N., Herzberg, D., and Daley, S.E. (2000). Toward an interpersonal life-stress model of depression: the developmental context of stress generation. Dev Psychopathol 12(2), 215-234. doi: 10.1017/s0954579400002066.

Sahu, P. (2020). Closure of Universities Due to Coronavirus Disease 2019 (COVID-19): Impact on Education and Mental Health of Students and Academic Staff. Cureus 12(4), e7541. doi: 10.7759/cureus.7541.

Salk, R.H., Hyde, J.S., and Abramson, L.Y. (2017). Gender differences in depression in representative national samples: Meta-analyses of diagnoses and symptoms. Psychol Bull 143(8), 783-822. doi: 10.1037/bu10000102.

Schulenberg, J.E., Sameroff, A.J., and Cicchetti, D. (2004). The transition to adulthood as a critical juncture in the course of psychopathology and mental health. Dev Psychopathol 16(4), 799-806. doi: $10.1017 / \mathrm{s} 0954579404040015$.

Spitzer, R.L., Kroenke, K., Williams, J.B., and Lowe, B. (2006). A brief measure for assessing generalized anxiety disorder: the GAD-7. Arch Intern Med 166(10), 1092-1097. doi: 10.1001/archinte.166.10.1092.

Valiente, C., Vázquez, C., Peinado, V., Contreras, A., Trucharte, A., Bentall, R., \& Martínez, A. (2020). VIDA-COVID-19 Estudio nacional representativo de las respuestas de los ciudadanos de España ante la crisis de Covid-19: respuestas psicológicas.

https://tribuna.ucm.es/revcul/tribunacomplutense/doc24997.pdf

Vollhardt, J.R. (2009). Altruism Born of Suffering and Prosocial Behavior Following Adverse Life Events: A Review and Conceptualization. Social Justice Research 22(1), 53-97. doi: 10.1007/s11211-009-0088-1. 
740 Wang, C., Horby, P.W., Hayden, F.G., and Gao, G.F. (2020a). A novel coronavirus outbreak of 741 global health concern. Lancet 395(10223), 470-473. doi: 10.1016/s0140-6736(20)30185-9.

742 Wang, C., and Zhao, H. (2020). The Impact of COVID-19 on Anxiety in Chinese University 743 Students. Front Psychol 11, 1168. doi: 10.3389/fpsyg.2020.01168.

Wang, Y., Di, Y., Ye, J., and Wei, W. (2020b). Study on the public psychological states and its related factors during the outbreak of coronavirus disease 2019 (COVID-19) in some regions of China. Psychology, Health \& Medicine, 1-10. doi: 10.1080/13548506.2020.1746817.

Waugh, C.E., Shing, E.Z., and Furr, R.M. (2020). Not all disengagement coping strategies are created equal: positive distraction, but not avoidance, can be an adaptive coping strategy for chronic life stressors. Anxiety Stress Coping, 1-19. doi: 10.1080/10615806.2020.1755820.

Wong, T.W., Gao, Y., and Tam, W.W.S. (2007). Anxiety among university students during the SARS epidemic in Hong Kong. Stress and Health 23(1), 31-35. doi: 10.1002/smi.1116.

World Health Organization (2020a). Coronavirus disease (COVID-19) pandemic. https://covid19.who.int/ [Accessed, July 6, 2020].

World Health Organization (2020b). Mental health considerations during the COVID-19 outbreak. http://www.who.int/docs/default-source/coronaviruse/mental-healthconsiderations.pdf?sfvrsn=6d3578af 2 [Accessed, July 6, 2020].

World Health Organization (2020c). WHO Coronavirus Disease (COVID-19) Dashboard. https://covid19.who.int/table [Accessed, July 6, 2020].

Wyatt, T., and Oswalt, S.B. (2013). Comparing Mental Health Issues Among Undergraduate and Graduate Students. American Journal of Health Education 44(2), 96-107. doi: 10.1080/19325037.2013.764248.

Zhai, Y., and Du, X. (2020). Addressing collegiate mental health amid COVID-19 pandemic. Psychiatry research 288, 113003-113003. doi: 10.1016/j.psychres.2020.113003.

Zhu, S., Wu, Y., Zhu, C.-Y., Hong, W.-C., Yu, Z.-X., Chen, Z.-K., et al. (2020). The immediate mental health impacts of the COVID-19 pandemic among people with or without quarantine managements. Brain, behavior, and immunity 87, 56-58. doi: 10.1016/j.bbi.2020.04.045.

Zivin, K., Eisenberg, D., Gollust, S.E., and Golberstein, E. (2009). Persistence of mental health problems and needs in a college student population. J Affect Disord 117(3), 180-185. doi: 10.1016/j.jad.2009.01.001. 
771 Table 1. Participants' main demographic variables and psycho-social characteristics.

\begin{tabular}{|c|c|c|}
\hline Variables & $\mathbf{N}$ & $\%$ \\
\hline \multicolumn{3}{|l|}{ Gender } \\
\hline Women & 704 & 75.5 \\
\hline Men & 222 & 23.8 \\
\hline Others & 6 & 0.6 \\
\hline \multicolumn{3}{|l|}{ Age } \\
\hline $18-20$ & 280 & 30.0 \\
\hline $21-23$ & 417 & 44.7 \\
\hline $24-26$ & 112 & 12.0 \\
\hline $27-29$ & 47 & 5.0 \\
\hline 30 or more & 76 & 8.2 \\
\hline \multicolumn{3}{|l|}{ University } \\
\hline Universidade de Santiago de Compostela & 661 & 70.9 \\
\hline Universidade de A Coruña & 38 & 4.1 \\
\hline Universidade de Vigo & 155 & 16.6 \\
\hline Others & 78 & 8.4 \\
\hline \multicolumn{3}{|l|}{ Level of education } \\
\hline Undergraduates & 810 & 86.9 \\
\hline Postgraduates & 85 & 9.1 \\
\hline PhD students & 37 & 4.0 \\
\hline \multicolumn{3}{|l|}{ Branch of knowledge } \\
\hline Arts and Humanities & 161 & 17.3 \\
\hline Experimental Sciences & 111 & 11.9 \\
\hline Health Sciences & 391 & 42.0 \\
\hline Engineering and Architecture & 84 & 9.0 \\
\hline Social and Legal Sciences & 183 & 19.7 \\
\hline \multicolumn{3}{|l|}{ Self-perceived social class } \\
\hline Low & 40 & 4.3 \\
\hline Low-middle & 245 & 26.3 \\
\hline Middle & 543 & 58.3 \\
\hline Middle-high & 102 & 10.9 \\
\hline High & 2 & 0.2 \\
\hline \multicolumn{3}{|c|}{ Diagnosed with a mental health problem before quarantine } \\
\hline Yes & 130 & 15.7 \\
\hline \multicolumn{3}{|l|}{ During quarantine } \\
\hline Returned to parent's home & 504 & 56.0 \\
\hline \multicolumn{3}{|l|}{ Being high risk COVID-19 people } \\
\hline Because of age & 16 & 1.8 \\
\hline Due to previous diseases & 102 & 11.3 \\
\hline Because being essential workers & 20 & 2.2 \\
\hline No & 770 & 85.6 \\
\hline \multicolumn{3}{|c|}{ Having lived with other high risk COVID-19 people } \\
\hline Because of age & 235 & 26.1 \\
\hline Due to previous diseases & 307 & 34.1 \\
\hline Because they work in the medical field & 109 & 12.1 \\
\hline Because being essential workers & 317 & 35.2 \\
\hline No & 290 & 32.2 \\
\hline \multicolumn{3}{|l|}{ Suffered COVID-19 } \\
\hline Myself & 8 & 0.9 \\
\hline Someone close to me & 206 & 22.9 \\
\hline No & 704 & 78.2 \\
\hline
\end{tabular}


773 Table 2. Descriptives of the main variables in the study.

\begin{tabular}{lcc}
\hline Variables & Mean (SD) & Range \\
\hline Psychological health & & \\
Anxiety & $10.82(5.00)$ & $0-21$ \\
Depression & $12.98(6.46)$ & $0-27$ \\
Irritability & $16.88(6.23)$ & $5-30$ \\
Changes in Mental health & $2.19(0.77)$ & $1-5$ \\
Stressors & & \\
Academic & $3.06(0.72)$ & $1-4$ \\
Social distancing & $2.94(0.66)$ & $1-4$ \\
Pandemic & $2.92(0.59)$ & $1-4$ \\
General overload & $2.84(0.78)$ & $1-4$ \\
Interpersonal conflict & $1.99(0.74)$ & $1-4$ \\
Coping & & \\
Other-oriented & $1.48(0.68)$ & $0-3$ \\
Reframing & $1.65(0.63)$ & $0-3$ \\
Routines & $1.39(0.84)$ & $0-3$ \\
Disengagement activities & $1.80(0.75)$ & $0-3$ \\
\hline
\end{tabular}

774

775 Table 3. Correlations between the constructs used in the path analysis.

\begin{tabular}{|c|c|c|c|c|c|c|c|c|c|c|c|c|c|}
\hline Variables & 1 & 2 & 3 & 4 & 5 & 6 & 7 & 8 & 9 & 10 & 11 & 12 & 13 \\
\hline 2. Social distancing & & & $0.36 * * *$ & $0.45^{* * *}$ & $0.42 * * *$ & $0.34 * * *$ & $*-0.05$ & 0.00 & $0.11 * *$ & $0.43^{* * *}$ & $0.40 * * *$ & $0.38 * * *$ & $-0.42 * * *$ \\
\hline 4. General overload & & & & & $0.35^{* * *}$ & $0.26^{* * *}$ & $*-0.02$ & $-0.09 *$ & -0.05 & $0.47^{* * *}$ & $0.43^{* * *}$ & $0.37 * * *$ & $-0.39 * * *$ \\
\hline 5. Interpersonal conflict & & & & & & $0.13^{* * *}$ & $*-0.04$ & -0.04 & -0.03 & $0.45^{* * *}$ & $0.43^{* * *}$ & $0.48^{* * *}$ & $-0.35 * * *$ \\
\hline 6. Other oriented & & & & & & & $0.27^{* * *}$ & $0.23 * * *$ & $0.31 * * *$ & $0.26 * * *$ & $0.15^{* * *}$ & $0.17^{* * *}$ & $-0.18 * * *$ \\
\hline 8. Routines & & & & & & & & & $0.30 * * *$ & $-0.12 * * *$ & $-0.28 * * *$ & $-0.10 * *$ & $0.20 * * *$ \\
\hline 9. Disengagement activities & & & & & & & & & & -0.06 & $-0.09 * *$ & -0.03 & $0.09 * *$ \\
\hline 10. Anxiety & & & & & & & & & & & $0.75^{* * *}$ & $0.70 * * *$ & $-0.57 * * *$ \\
\hline 11. Depression & & & & & & & & & & & & $0.63 * * *$ & $-0.57^{* * *}$ \\
\hline 12. Irritability & & & & & & & & & & & & & $-0.50 * * *$ \\
\hline 13. Self-perceived change & & & & & & & & & & & & & \\
\hline
\end{tabular}


777 Table 4. Standardized and unstandardized regression weights, standard errors, $\mathrm{z}$ values, and 778 associated $p$-values for coping.

\begin{tabular}{cccccccc}
\hline Coping & & Stressor & SRW & URW & SE & C.R. & $\boldsymbol{p}$-value \\
\hline Other oriented & $<---$ & Social distancing & 0.20 & 0.20 & 0.03 & 5.58 & 0.000 \\
Other oriented & $<---$ & Pandemic & 0.22 & 0.24 & 0.03 & 6.35 & 0.000 \\
Other oriented & $<---$ & General overload & 0.10 & 0.09 & 0.03 & 3.01 & 0.003 \\
Reframing & $<---$ & Social distancing & -0.10 & -0.09 & 0.03 & -2.77 & 0.005 \\
Reframing & $<---$ & Pandemic & 0.13 & 0.13 & 0.03 & 3.54 & 0.000 \\
Routines & $<---$ & Academic & -0.13 & -0.19 & 0.04 & -3.32 & 0.000 \\
Routines & $<---$ & Social distancing & 0.08 & 0.10 & 0.05 & 2.06 & 0.039 \\
Routines & $<---$ & Pandemic & 0.13 & 0.19 & 0.05 & 3.48 & 0.009 \\
Routines & $<---$ & General overload & -0.09 & -0.09 & 0.04 & -2.30 & 0.021 \\
Disengagement activities & $<---$ & Social distancing & 0.12 & 0.14 & 0.04 & 3.21 & 0.001 \\
Disengagement activities & $<---$ & Pandemic & 0.11 & 0.14 & 0.04 & 2.96 & 0.003 \\
Disengagement activities & $<---$ & General overload & -0.14 & -0.13 & 0.03 & -3.87 & 0.000 \\
\hline
\end{tabular}

NOTE: SRW (Standardized Regression Weights), URW (Unstandardized Regression Weights), SE (Standard Error)

780 Table 5. Standardized and unstandardized regression weights, standard errors, $\mathrm{z}$ values, and 781 associated $p$-values for health-related indicators.

\begin{tabular}{cccccccc}
\hline Health-related indicator & & Coping & SRW & URW & SE & C.R. & $\boldsymbol{p}$-value \\
\hline Anxiety & $<---$ & Other oriented & 0.08 & 0.61 & 0.17 & 3.63 & 0.000 \\
Anxiety & $<--$ & Reframing & -0.14 & -1.09 & 0.22 & -4.84 & 0.000 \\
Anxiety & $<--$ & Disengagement activities & -0.05 & -0.32 & 0.14 & -2.26 & 0.023 \\
Depression & $<---$ & Reframing & -0.12 & -1.24 & 0.29 & -4.28 & 0.000 \\
Depression & $<---$ & Routines & -0.18 & -1.37 & 0.17 & -7.96 & 0.000 \\
Irritability & $<---$ & Reframing & -0.10 & -0.97 & 0.28 & -3.42 & 0.000 \\
Self-perceived change & $<---$ & Other oriented & -0.07 & -0.08 & 0.03 & -2.43 & 0.015 \\
Self-perceived change & $<---$ & Reframing & 0.19 & 0.24 & 0.03 & 6.33 & 0.000 \\
Self-perceived change & $<---$ & Routines & 0.10 & 0.09 & 0.02 & 3.63 & 0.000 \\
\hline
\end{tabular}

NOTE: SRW (Standardized Regression Weights), URW (Unstandardized Regression Weights), SE (Standard Error) 
790 Table 6. Path analysis testing the indirect effects of the variables that entered into the model.

\begin{tabular}{|c|c|c|c|c|c|c|}
\hline $\begin{array}{l}\text { Variables } \\
\text { Anxiety }\end{array}$ & \multicolumn{2}{|c|}{$\begin{array}{c}\text { Total effects } \\
\beta(90 \% \mathrm{Cl})\end{array}$} & \multicolumn{2}{|c|}{$\begin{array}{c}\text { Direct effect } \\
\beta(90 \% \mathrm{Cl})\end{array}$} & \multicolumn{2}{|c|}{$\begin{array}{c}\text { Indirect effect } \\
\beta(90 \% \mathrm{Cl})\end{array}$} \\
\hline General overload & $0.21^{* * *}$ & $(0.15,0.27)$ & $0.20 * * *$ & $(0.14,0.26)$ & $0.01^{* *}$ & $(0.00,0.02)$ \\
\hline Pandemic & $0.08 * *$ & $(0.04,0.12)$ & $0.09 * * *$ & $(0.05,0.13)$ & -0.00 & $(-0.01,0.00)$ \\
\hline Social distancing & $0.13^{* * *}$ & $(0.07,0.19)$ & $0.11^{* *}$ & $(0.05,0.17)$ & $0.02 * *$ & $(0.01,0.04)$ \\
\hline Interpersonal conflict & $0.23 * * *$ & $(0.17,0.28)$ & $0.23 * * *$ & $(0.17,0.28)$ & - & - \\
\hline Academic & $0.14 * * *$ & $(0.07,0.20)$ & $0.14 * * *$ & $(0.07,0.20)$ & - & - \\
\hline \multicolumn{7}{|l|}{ Depression } \\
\hline General overload & $0.19 * * *$ & $(0.13,0.25)$ & $0.17 * * *$ & $(0.11,0.23)$ & $0.01^{*}$ & $(0.00,0.03)$ \\
\hline Pandemic & $-0.04 * * *$ & $(-0.06,-0.02)$ & - & - & $-0.04 * * *$ & $(-0.06,-0.02)$ \\
\hline Social distancing & $0.15^{* * *}$ & $(0.08,0.21)$ & $0.15^{* * *}$ & $(0.09,0.21)$ & -0.00 & $(-0.02,0.01)$ \\
\hline Interpersonal conflict & $0.23 * *$ & $(0.18,0.29)$ & $0.23 * *$ & $(0.18,0.29)$ & - & - \\
\hline Academic & $0.16 * * *$ & $(0.10,0.22)$ & $0.13 * * *$ & $(0.08,0.19)$ & $0.02 * *$ & $(0.01,0.03)$ \\
\hline \multicolumn{7}{|l|}{ Irritability } \\
\hline General overload & $0.12^{* *}$ & $(0.06,0.18)$ & $0.12^{* *}$ & $(0.06,0.18)$ & - & - \\
\hline Pandemic & $-0.01 * * *$ & $(-0.02,-0.00)$ & - & - & $-0.01 * * *$ & $(-0.02,-0.00)$ \\
\hline Social distancing & $0.12^{* * *}$ & $(0.06,0.18)$ & $0.11 * *$ & $(0.05,0.17)$ & $0.01 * *$ & $(0.00,0.02)$ \\
\hline Interpersonal conflict & $0.35^{* * *}$ & $(0.29,0.40)$ & $0.35 * * *$ & $(0.29,0.40)$ & - & - \\
\hline Academic & $0.09 *$ & $(0.03,0.15)$ & $0.09 *$ & $(0.03,0.15)$ & - & - \\
\hline \multicolumn{7}{|l|}{$\begin{array}{l}\text { Self-perceived } \\
\text { change }\end{array}$} \\
\hline General overload & $-0.14^{* *}$ & $(-0.20,-0.07)$ & $-0.12^{* *}$ & $(-0.18,-0.05)$ & $-0.01 * *$ & $(-0.03,-0.00)$ \\
\hline Pandemic & $0.02 *$ & $(0.00,0.04)$ & - & - & $0.02 *$ & $(0.00,0.04)$ \\
\hline Social distancing & $-0.23 * * *$ & $(-0.30,-0.17)$ & $-0.20 * * *$ & $(-0.27,-0.14)$ & $-0.02 *$ & $(-0.04,-0.00)$ \\
\hline Interpersonal conflict & $-0.13^{* *}$ & $(-0.19,-0.07)$ & $-0.13^{* *}$ & $(-0.19,-0.07)$ & - & - \\
\hline Academic & $-0.18 * * *$ & $(-0.25,-0.17)$ & $-0.16 * * *$ & $(-0.23,-0.10)$ & $-0.01 * *$ & $(-0.02,-0.00)$ \\
\hline
\end{tabular}




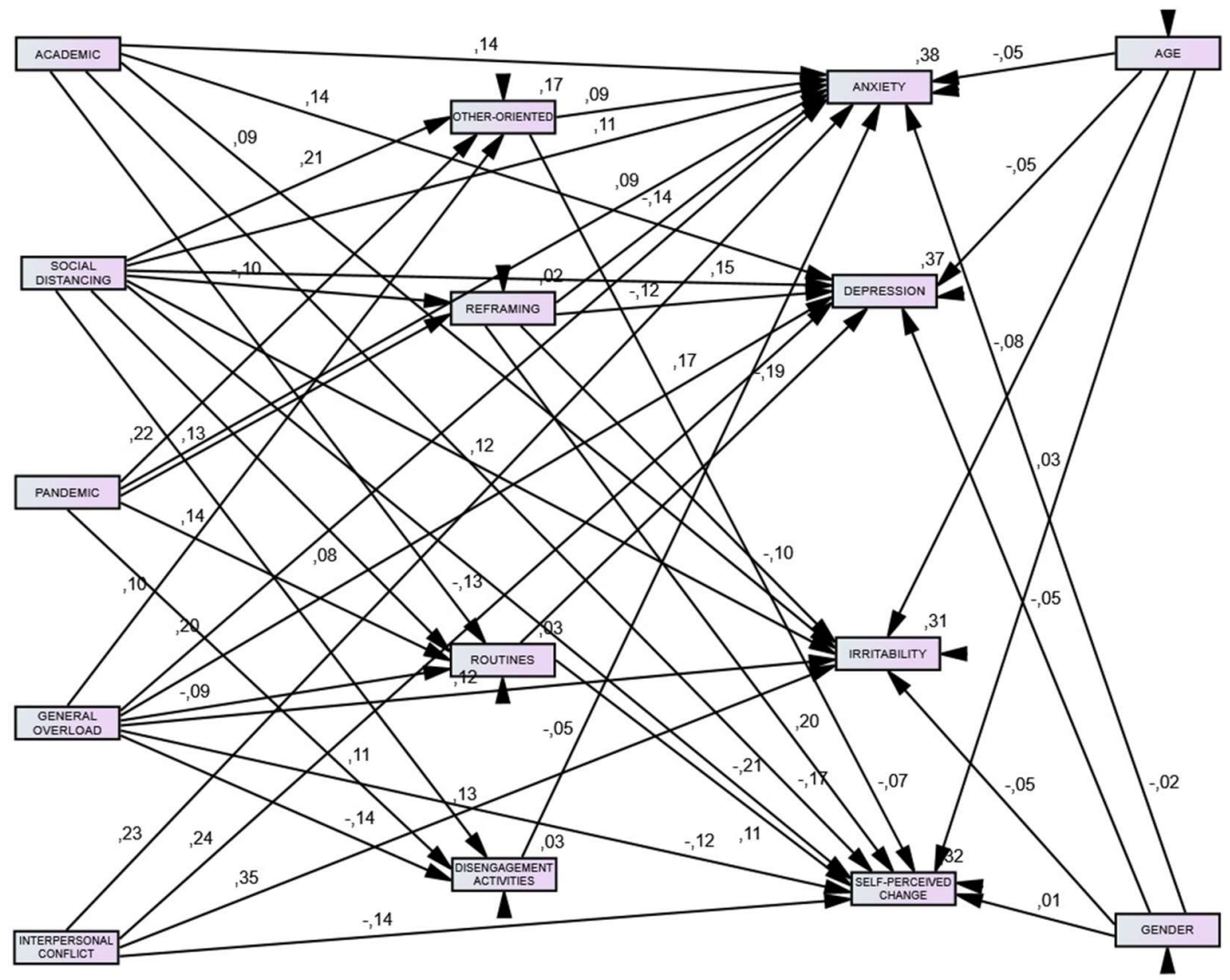

796 Figure 1. Relationship between stressors, coping, and health-related indicators. All reported path coefficients $(p<0.05)$ are standardized estimates. Terms of error, correlations, and covariances were 798 omitted for clarity. 


\section{Supplementary Material}

Table 1S. Distribution of items across the five stressor domains, along with means and SDs for this study.

\begin{tabular}{|c|c|c|}
\hline Stressors & Mean (SD) & Range \\
\hline \multicolumn{3}{|l|}{ Academic stressors $(\alpha=0.80, \mathrm{MIC}=0.40)$} \\
\hline Academic future in the long-term & $3.16(0.98)$ & $1-4$ \\
\hline Academic record damages due to the COVID-19 crisis & $2.91(1.08)$ & $1-4$ \\
\hline Laboral future & $3.11(1.06)$ & $1-4$ \\
\hline Not receiving the expected academic training & $3.16(0.95)$ & $1-4$ \\
\hline Uncertainty about academic evaluation & $3.45(0.91)$ & $1-4$ \\
\hline Financial difficulties & $2.60(1.07)$ & $1-4$ \\
\hline \multicolumn{3}{|l|}{ Social distancing $(\alpha=0.71, \mathrm{MIC}=0.34)$} \\
\hline Lack of face-to-face contact (with loved ones) & $3.30(0.82)$ & $1-4$ \\
\hline Staying at home for so long & $2.98(1.00)$ & $1-4$ \\
\hline Upcoming lifestyle changes due the COVID-19 crisis & $3.12(0.89)$ & $1-4$ \\
\hline Loneliness & $2.61(1.13)$ & $1-4$ \\
\hline Delaying or cancelling plans & $2.73(1.00)$ & $1-4$ \\
\hline \multicolumn{3}{|l|}{ Pandemic $(\alpha=0.73, \mathrm{MIC}=0.36)$} \\
\hline The risk of loved ones (or yourself) become infected & $2.90(0.90)$ & $1-4$ \\
\hline The human losses (caused by COVID-19) & $3.06(0.88)$ & $1-4$ \\
\hline Someone close (or yourself) being affected by COVID-19 & $1.93(1.01)$ & $1-4$ \\
\hline The economic future of society & $3.40(0.71)$ & $1-4$ \\
\hline The uncertainty about the COVID-19 crisis & $3.36(0.76)$ & $1-4$ \\
\hline \multicolumn{3}{|l|}{ General overload $(\alpha=.71, \mathrm{MIC}=0.39)$} \\
\hline The academic homework overload & $3.12(1.06)$ & $1-4$ \\
\hline Difficulties adapting to online learning & $2.93(1.06)$ & $1-4$ \\
\hline Lack of free time & $2.53(1.12)$ & $1-4$ \\
\hline The impossibility of dedicating time to hobbies and interests & $2.80(1.00)$ & $1-4$ \\
\hline \multicolumn{3}{|l|}{ Interpersonal conflicts $(\alpha=0.69, \mathrm{MIC}=0.35)$} \\
\hline (Intensification of) family conflicts & $2.26(1.12)$ & $1-4$ \\
\hline Worsening cohabit relations & $2.50(1.08)$ & $1-4$ \\
\hline Looking after other people & $1.68(0.91)$ & $1-4$ \\
\hline Breaking-up with partner & $1.53(0.96)$ & $1-4$ \\
\hline
\end{tabular}


Table 2S. Distribution of items across the four domains of coping strategies, along with means and SDs for this study.

\begin{tabular}{|c|c|c|}
\hline Coping Strategies & Mean (SD) & Range \\
\hline \multicolumn{3}{|l|}{ Oriented to others $(\alpha=0.72, \mathrm{MIC}=0.40)$} \\
\hline Looking for understanding and emotional support from others & $1.63(0.95)$ & $0-3$ \\
\hline Trying to get help and advice from other people & $1.15(0.88)$ & $0-3$ \\
\hline Expressing negative feelings & $1.44(0.99)$ & $0-3$ \\
\hline Helping others with their own difficulties & $1.72(0.81)$ & $0-3$ \\
\hline \multicolumn{3}{|l|}{ Reframing $(\alpha=0.57, \mathrm{MIC}=0.31)$} \\
\hline Accepting the fact that this is happening and adapting to the situation & $2.02(0.77)$ & $0-3$ \\
\hline Looking for something good in what is happening & $1.35(0.96)$ & $0-3$ \\
\hline Concentrating efforts on looking for a solution to resolve difficulties & $1.57(0.81)$ & $0-3$ \\
\hline \multicolumn{3}{|l|}{ Activities $(\alpha=0.70$, MIC $=0.54)$} \\
\hline Doing something to be distracted from difficulties & $1.88(0.87)$ & $0-3$ \\
\hline Doing relaxing activities & $1.73(0.85)$ & $0-3$ \\
\hline \multicolumn{3}{|l|}{ Routines $(\alpha=0.63, \mathrm{MIC}=0.46)$} \\
\hline Trying to keep some routines and schedules & $1.45(0.97)$ & $0-3$ \\
\hline Taking care of one's health (nutrition, exercise...) to be psychologically stronger & $1.35(1.01)$ & $0-3$ \\
\hline \multicolumn{3}{|l|}{ Items which did not load in any factor } \\
\hline Trying to find relief in my spiritual or religious beliefs & $0.25(0.61)$ & $0-3$ \\
\hline Making fun of the situation & $1.23(0.97)$ & $0-3$ \\
\hline Consuming alcohol or other substances to feel better & $0.29(0.67)$ & $0-3$ \\
\hline
\end{tabular}

